\title{
A utilização da fibrina rica em plaquetas em procedimentos estéticos orofaciais: uma revisão integrativa
}

\author{
The use of platelet-rich fibrin in orofacial aesthetic procedures: an integrative review \\ El uso de fibrina rica en plaquetas en procedimientos estéticos orofaciales: una revisión integradora
}

Recebido: 02/03/2021 | Revisado: 07/03/2021 | Aceito: 08/03/2021 | Publicado: 16/03/2021

\author{
Vânia Feitosa Lins \\ ORCID: https://orcid.org/0000-0002-6512-2741 \\ Universidade Federal de Alagoas, Brasil \\ E-mail: vanialins93@gmail.com \\ Diogo Gomes Brandão \\ ORCID: https://orcid.org/0000-0001-6167-0399 \\ Universidade Federal de Alagoas, Brasil \\ E-mail: diogo.brandao2009@hotmail.com \\ Stela Maris Wanderley Rocha \\ ORCID: https://orcid.org/0000-0002-3220-648X \\ Universidade Federal de Alagoas, Brasil \\ E-mail: stelawanderley@hotmail.com
}

\begin{abstract}
Resumo
Os concentrados plaquetários são utilizados com finalidade terapêutica em seres humanos a mais de 60 anos, apresentando resultados promissores, visto que a obtenção destas plaquetas é feita a partir do sangue autógeno do paciente. O PRF faz parte da segunda geração desses concentrados, de obtenção simplificada e sem a adição de produtos bioquímicos. Atualmente, esses concentrados se tornaram cada vez mais específicos, o que favoreceu sua utilização em diversas áreas, dentre elas vem sendo investigada como uma ferramenta para procedimentos estéticos na região orofacial. O objetivo deste trabalho foi realizar uma revisão integrativa de literatura e analisar estudos sobre a utilização do PRF como adjuvante na harmonização orofacial, suas metodologias e resultados, afim de avaliar a eficácia da técnica. Os artigos compilados neste estudo foram selecionados por meio das bases de dados: PubMed, Medline e Scielo. O levantamento limitou-se aos artigos publicados nos idiomas inglês e português, entre os anos de 2010 a 2020. Embora existam poucos estudos específicos que envolvam essas duas áreas de concentração, os resultados apontam que o PRF injetável tem se mostrado eficaz quando utilizada em procedimentos estéticos orofaciais, respondendo de forma efetiva na regeneração dos tecidos. Destarte, o uso dessa técnica pode trazer benefícios profícuos para os pacientes, porém ainda deve haver maior divulgação e estudos científicos, objetivando o aprimoramento da técnica e a padronização dos protocolos.
\end{abstract}

Palavras-chave: Fibrina rica em plaquetas; Envelhecimento cutâneo; Regeneração da pele por plasma.

\begin{abstract}
Platelet concentrates have been used for therapeutic purposes in humans for more than 60 years, showing promising results, since these platelets are obtained from the patient's autogenous blood. The PRF is part of the second generation of these concentrates, obtainable simplified and without the addition of biochemical products. Currently, these concentrates have become increasingly specific, which has favored their use in several areas, among them has been investigated as a tool for aesthetic procedures in the orofacial region. The objective of this work was to carry out an integrative literature review and analyze studies on the use of PRF as an adjunct in orofacial harmonization, its methodologies and results, in order to assess the effectiveness of the technique. The articles compiled in this study were selected through the databases: PubMed, Medline and Scielo. The survey was limited to articles published in the English and Portuguese languages, between the years 2010 to 2020. Although there are few specific studies involving these two areas of concentration, the results show that injectable PRF has been shown to be effective when used in procedures orofacial esthetics, responding effectively to tissue regeneration. Thus, the use of this technique can bring beneficial benefits to patients, but there must still be greater dissemination and scientific studies, aiming at improving the technique and standardizing the protocols.
\end{abstract}

Keywords: Platelet rich fibrin; Skin aging; Plasma skin regeneration.

\section{Resumen}

Los concentrados de plaquetas se han utilizado con fines terapéuticos en humanos desde hace más de 60 años, mostrando resultados prometedores, ya que estas plaquetas se obtienen de la sangre autógena del paciente. El PRF es parte de la segunda generación de estos concentrados, obtenibles de forma simplificada y sin la adición de productos bioquímicos. Actualmente, estos concentrados se han vuelto cada vez más específicos, lo que ha favorecido su uso en 
varias áreas, entre ellas se ha investigado como herramienta para procedimientos estéticos en la región orofacial. El objetivo de este trabajo fue realizar una revisión integradora de la literatura y analizar estudios sobre el uso de PRF como coadyuvante en la armonización orofacial, sus metodologías y resultados, con el fin de evaluar la efectividad de la técnica. Los artículos recopilados en este estudio fueron seleccionados a través de las bases de datos: PubMed, Medline y Scielo. La encuesta se limitó a artículos publicados en inglés y portugués, entre los años 2010 a 2020. Aunque existen pocos estudios específicos que involucren estas dos áreas de concentración, los resultados muestran que la PRF inyectable ha demostrado ser efectiva cuando se utiliza en procedimientos de estética orofacial , respondiendo eficazmente a la regeneración de tejidos. Así, el uso de esta técnica puede traer beneficios beneficiosos a los pacientes, pero aún debe haber una mayor difusión y estudios científicos, con el objetivo de mejorar la técnica y estandarizar los protocolos.

Palabras clave: Fibrina rica en plaquetas; Envejecimiento de la piel; Regeneración cutánea con plasma.

\section{Introdução}

A face é a região do corpo que nos permite além de nos relacionarmos diretamente com o mundo é também o local onde estão nossas características individuais, estreitamente associada à nossa autoestima e reconhecimento (Oliveira e Sarmento, 2019). Através da face executamos os movimentos faciais onde expressamos emoções e sentimentos (Gračanin et al., 2017). O processo fisiológico de envelhecimento induz a perda de gordura subcutânea e do colágeno dérmico resultando em sulcos e depressões na face (Novais \& Souza, 2020).

Portanto, com passar do tempo todos irão envelhecer, corroborando para que as linhas de expressão faciais se tornem acentuadas com o avanço progressivo da idade, potencializadas pela ação muscular, perda volumétrica da face e exposição a fatores individuais como o estilo de vida e características genéticas. Assim, o envelhecimento é um processo irreversível, paulatino e moroso, entretanto com o crescimento da expectativa de vida aliada a valorização da juventude e do belo, fez com que as pessoas se preocupem cada vez mais com a aparência facial (Pairol et al., 2019; Silva \& Rodrigues, 2020).

Atualmente muitas pessoas desejam envelhecer e manter a aparência jovial, livre de rugas e marcas de expressão, deste modo os tratamentos estéticos de rejuvenescimento facial tornaram-se cada vez mais presentes dentro dos atendimentos clínicos, justificado pelo aumento dos gastos em procedimentos estéticos e cosméticos (Henrique \& Lopes, 2017; Sinigaglia \& Führ, 2019). Para amenizar o percurso inevitável do envelhecimento muitas técnicas foram desenvolvidas seja o tratamento preventivo ou paliativo do rejuvenescimento facial (Figueira et al., 2021).

Dentre uma gama de produtos, medicamentos, equipamentos e procedimentos cirúrgicos, que já são empregados buscando o rejuvenescimento da face ao longo de décadas. Atualmente, as aplicações de concentrados plaquetários autólogos, com ênfase aos de segunda geração, estão sendo previamente investigados como uma modalidade terapêutica para os procedimentos de estética orofacial (Silva et al., 2016; Aires et al., 2019).

Conhecida como um agregado plaquetário de segunda geração, a fibrina rica em plaquetas (PRF) é obtida como uma membrana de alto potencial técnico de regeneração tecidual. As plaquetas contidas no PRF liberam fatores de crescimento atuando como um arcabouço biodegradável que favorece a regulação do processo inflamatório e estimulam a resposta imune através da quimiotaxia. De obtenção simples e com baixo custo clínico, essa categoria de concentrados fornece uma possível alternativa terapêuticas com resultados promissores, visto que utiliza um material autógeno, propício a estimulação fisiológica cicatricial e regenerativa (Otárola et al., 2016; Tchemra et al., 2021).

Em consonância ao exposto, justifica-se este estudo para análise das informações científicas dos benefícios clínicos da fibrina rica em plaquetas nos procedimentos estéticos orofaciais, compreendendo o mecanismo de rejuvenescimento facial e identificar possíveis complicações biológicas inerentes a este tratamento, tendo em vista sua recente utilização como artifício terapêutico na odontologia regenerativa e harmonização orofacial. 


\section{Metodologia}

Trata-se de um estudo de revisão integrativa da literatura, que se refere a um tipo de pesquisa que possibilita a síntese e a análise do conhecimento científico sobre o tema investigado. O propósito deste método é construir um profundo entendimento de um determinado fenômeno tendo como referência os estudos previamente realizados, seguindo as seis fases do processo de elaboração da revisão integrativa: elaboração da pergunta norteadora, busca ou amostragem na literatura, coleta de dados, análise crítica dos estudos incluídos, discussão dos resultados e formulação da revisão integrativa (Souza, Silva \& Carvalho, 2010; Pereira et al., 2018).

Foi realizada uma pesquisa bibliográfica sobre os dois temas centrais que envolveram a seguinte pergunta norteadora: Qual a eficácia da utilização da fibrina rica em plaquetas nos procedimentos estéticos orofaciais?

A partir da utilização das bases de dados PUBMED, LILACS, e SCIELO foi realizada a seleção de trabalhos entre maio a setembro de 2020, utilizando os descritores padronizados pelo Descritores em Ciências da Saúde (Decs): Fibrina Rica em Plaquetas; Envelhecimento Cutâneo; Regeneração da Pele por Plasma, e seus correspondentes em inglês. Em todas as combinações foi utilizado o operador booleano And. O levantamento limitou-se aos artigos publicados em língua portuguesa e inglesa, indexados nas bases de dados entre os anos de 2010 e 2020.

Os estudos foram refinados inicialmente pelos títulos, selecionados pelos resumos. Após leitura dos resumos, os artigos que indicavam corresponder ao objetivo desta revisão, foram lidos integralmente, e uma vez que preencheram os critérios de inclusão, participaram deste estudo.

Portanto, para que os artigos encontrados nas bases de dados pudessem serem incluídos no estudo, utilizaram-se os seguintes critérios: estar em formato de artigo, possuírem título e resumo que se assemelhem aos objetivos do trabalho e estar publicado na íntegra. Excluíram-se todos os artigos que não contemplaram a estes critérios, conforme ilustrado na Figura 1.

Figura 1: Etapas da coleta de dados de estudo.

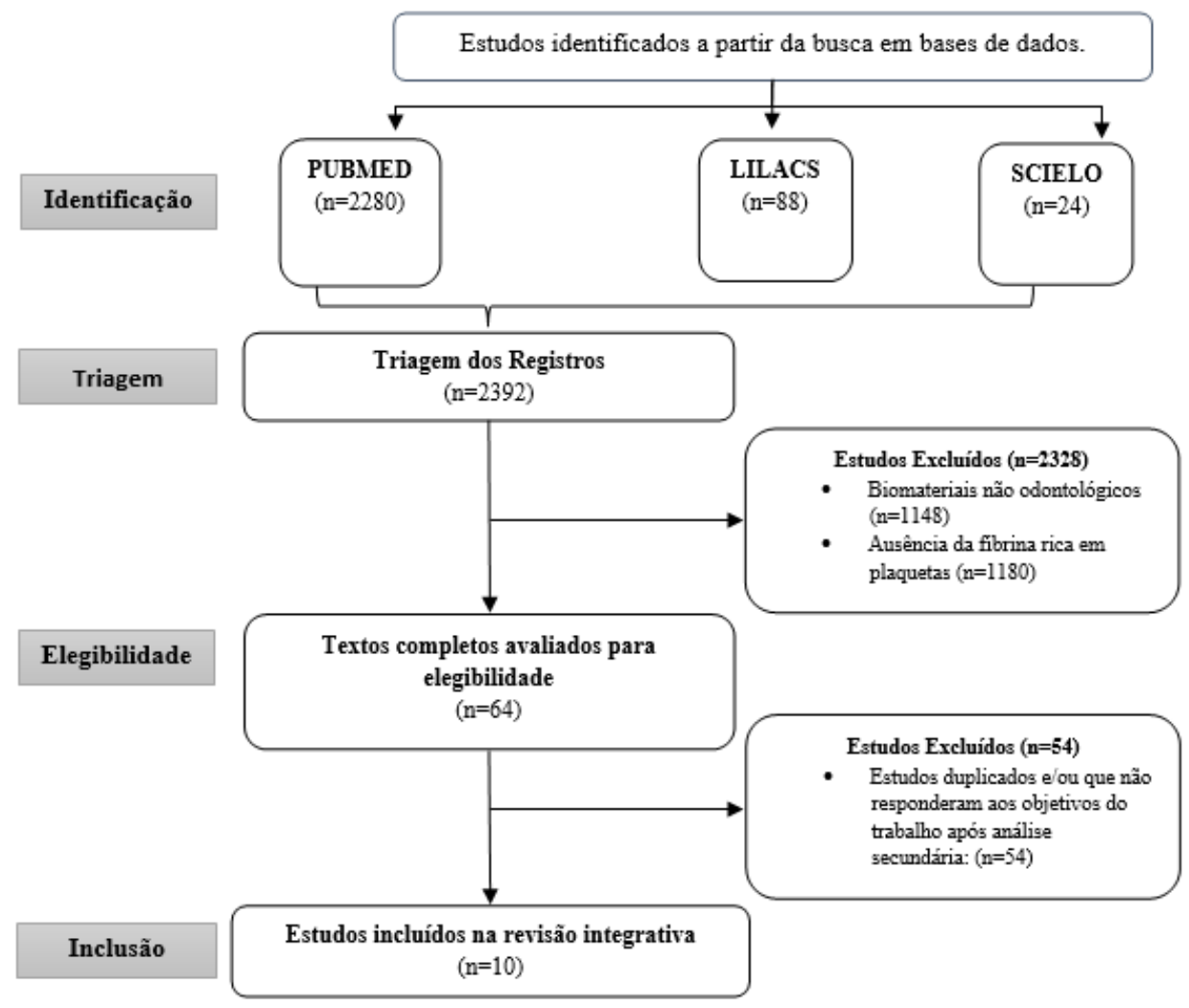

Fonte: Autores (2021). 


\section{Resultados}

Empregando as palavras: Fibrina Rica em Plaquetas; Envelhecimento Cutâneo; Regeneração da Pele por Plasma, foram encontrados um total de 2392 artigos nas bases de dados PubMed, Lilacs e Scielo, nos idiomas escolhidos. Sendo 2308 artigos destes excluídos na leitura de título, dos 84 trabalhos que restaram, 20 foram descartados na leitura de resumos. Ao final, 64 artigos estavam disponíveis para leitura na íntegra, onde destes, 54 foram excluídos por duplicação. Ao final, restaram 10 artigos que estavam de acordo com os critérios de inclusão do presente estudo.

Os trabalhos avaliados no Quadro 1, indicam que o emprego da fibrina rica em plaquetas de administração tópica ou injetáveis, tem efeitos significativos nos tratamentos estéticos da face e otimizam a cicatrização de feridas, entretanto ao visualizar os trabalhos realizados nos últimos 10 anos, deve-se considerar a necessidade de conduzir trabalhos clínicos mais robustos e abrangentes com essa temática, tendo em vista a necessidade de apresentar evidências científicas nos tratamentos destes indivíduos e ajudar os profissionais da harmonização orofacial na tomada de decisões mais eficazes.

Quadro 1: Síntese de publicações incluídas na revisão integrativa, entre os anos 2010 e 2020 segundo as bases de dados PubMed, Lilacs e Scielo.

\begin{tabular}{|c|c|c|c|c|}
\hline Título e Autores & Ano & Delineamento & Objetivos & Desfecho \\
\hline $\begin{array}{l}\text { Platelet-rich fibrin matrix for } \\
\text { improvement of deep } \\
\text { nasolabial folds } \\
\text { (Sclafani et al) }\end{array}$ & 2010 & Estudo Qualitativo & $\begin{array}{l}\text { Avaliar a eficácia da } \\
\text { fibrina rica em plaquetas } \\
\text { para a correção de sulcos } \\
\text { nasolabiais profundos. }\end{array}$ & $\begin{array}{l}\text { O estudo mostrou que a fibrina rica } \\
\text { em plaquetas diminuiu } \\
\text { significativamente sulcos nasolabiais } \\
\text { profundos a longo prazo, além de } \\
\text { provocar aumento na estimulação } \\
\text { cutânea. }\end{array}$ \\
\hline $\begin{array}{l}\text { Platelet-Rich Fibrin Matrix for } \\
\text { facial plastic surgery } \\
\text { (Sclafani e Saman) }\end{array}$ & 2012 & Estudo Qualitativo & $\begin{array}{l}\text { Descrever algumas } \\
\text { aplicações extraorais da } \\
\text { fibrina rica em plaquetas } \\
(\mathrm{PRF}) \text { na face. }\end{array}$ & $\begin{array}{l}\text { Revelou-se que a matriz de PRF } \\
\text { estimula os vasos sanguíneos, e } \\
\text { melhora a capacidade natural de } \\
\text { cicatrização de feridas no paciente, } \\
\text { sendo um biomaterial com alto poder } \\
\text { regenerativo. }\end{array}$ \\
\hline $\begin{array}{l}\text { Platelet preparations for use in } \\
\text { facial rejuvenation and wound } \\
\text { healing: a critical review of } \\
\text { current literature } \\
\text { (Sclafani e Azzi) }\end{array}$ & 2015 & $\begin{array}{l}\text { Revisão de } \\
\text { Literatura }\end{array}$ & $\begin{array}{lrr}\text { Analisar } & 61 & \text { estudos } \\
\text { realizados } & \text { por } & \text { diferentes } \\
\text { autores } & \text { quanto } & \text { a } \\
\text { utilização } & \text { de } & \text { preparos } \\
\text { plaquetários } & \text { em } \\
\text { procedimentos } & \text { estéticos } \\
\text { faciais. } & & \end{array}$ & $\begin{array}{l}\text { Verificou-se nos estudos examinados } \\
\text { um efeito significativo na } \\
\text { cicatrização de feridas e no resultado } \\
\text { estético facial satisfatório com o uso } \\
\text { de preparos plaquetários, tanto } \\
\text { tópicos quanto injetáveis. }\end{array}$ \\
\hline $\begin{array}{l}\text { Injectable platelet rich fibrin (i- } \\
\text { PRF): opportunities in } \\
\text { regenerative dentistry? }\end{array}$ & 2016 & $\begin{array}{c}\text { Estudo } \\
\text { Experimental }\end{array}$ & $\begin{array}{l}\text { Avaliar a relevância } \\
\text { clínica da fibrina rica em } \\
\text { plaquetas injetável na } \\
\text { odontologia, quando } \\
\text { comparado a fibrina rica } \\
\text { em plaquetas em } \\
\text { procedimentos estéticos. }\end{array}$ & $\begin{array}{l}\text { Os estudos demonstraram que fibrina } \\
\text { rica em plaquetas injetável teve } \\
\text { capacidade de liberar concentrações } \\
\text { mais elevadas de vários fatores de } \\
\text { crescimento e induziu maior } \\
\text { migração de fibroblastos, sendo } \\
\text { assim mais eficiente para reposição } \\
\text { de colágeno nos procedimentos de }\end{array}$ \\
\hline
\end{tabular}


Research, Society and Development, v. 10, n. 3, e27910313477, 2021

(CC BY 4.0) | ISSN 2525-3409 | DOI: http://dx.doi.org/10.33448/rsd-v10i3.13477

\begin{tabular}{|c|c|c|c|c|}
\hline & & & & estética facial. \\
\hline $\begin{array}{l}\text { Telomere length and genetic } \\
\text { variations affecting telomere } \\
\text { length as biomarkers for facial } \\
\text { regeneration with platelet-rich } \\
\text { fibrin based on the low-speed } \\
\text { centrifugation concept } \\
\text { (Nacopolous et al.) }\end{array}$ & 2018 & $\begin{array}{c}\text { Estudo de } \\
\text { Experimental }\end{array}$ & $\begin{array}{l}\text { Avaliar uma combinação } \\
\text { de (PRF) liquido injetável } \\
\text { no processo de } \\
\text { regeneração da pele, } \\
\text { usando os conceitos de } \\
\text { centrifugação de baixa } \\
\text { velocidade. }\end{array}$ & $\begin{array}{l}\text { Foi demonstrado que as matrizes de } \\
\text { fibrina rica em plaquetas, possui } \\
\text { resultados significativos na } \\
\text { regeneração da pele e nos sinais de } \\
\text { envelhecimento. }\end{array}$ \\
\hline $\begin{array}{l}\text { Fibrina rica em plaquetas: } \\
\text { preparo, definição da } \\
\text { qualidade, uso clínico } \\
\text { (Takamori et al.) }\end{array}$ & 2018 & Revisão Integrativa & $\begin{array}{l}\text { Aquilatar o preparo, } \\
\text { controle de qualidade e } \\
\text { uso clínico da fibrina rica } \\
\text { em plaquetas. }\end{array}$ & $\begin{array}{l}\text { Os estudos concluíram que, por ser } \\
\text { uma matriz de fibrina, rica em } \\
\text { plaquetas, libera numerosos } \\
\text { mediadores regenerativos, sendo um } \\
\text { material com excelentes resultados. }\end{array}$ \\
\hline $\begin{array}{l}\text { Injectable platelet rich fibrin: } \\
\text { cell content, morphological, } \\
\text { and protein characterization } \\
\text { (Varela et al.) }\end{array}$ & 2018 & Estudo Qualitativo & $\begin{array}{l}\text { Averiguar o conteúdo das } \\
\text { células sanguíneas e seus } \\
\text { aspectos morfológicos em } \\
\text { uma fibrina rica em } \\
\text { plaquetas injetável (i- } \\
\text { PRF). }\end{array}$ & $\begin{array}{l}\text { O estudo revelou uma concentração } \\
\text { mais elevada de plaquetas e } \\
\text { linfócitos no (i-PRF) quando } \\
\text { comparados aqueles do sangue } \\
\text { periférico, tornando o i-PRF uma } \\
\text { boa abordagem para a cicatrização } \\
\text { de tecidos moles faciais. }\end{array}$ \\
\hline $\begin{array}{c}\text { Fluid platelet-rich fibrin } \\
\text { stimulates greater dermal skin } \\
\text { fibroblast cell migration, } \\
\text { proliferation, and collagen } \\
\text { synthesis when compared to } \\
\text { platelet-rich plasma } \\
\text { (Wang et al.) }\end{array}$ & 2019 & $\begin{array}{c}\text { Estudo } \\
\text { Comparativo }\end{array}$ & $\begin{array}{l}\text { Verificar qual o } \\
\text { comportamento do } \\
\text { concentrado de fibrinas } \\
\text { rico em plaquetas na } \\
\text { regeneração das células } \\
\text { da pele. }\end{array}$ & $\begin{array}{l}\text { Os dados encontrados indicam que a } \\
\text { fibrina rica em plaquetas estimula a } \\
\text { migração de fibroblastos da pele, } \\
\text { além de melhorar a síntese de } \\
\text { colágeno. }\end{array}$ \\
\hline $\begin{array}{c}\text { The benefits of platelet rich } \\
\text { fibrin } \\
\text { (Karimi e Rockwell) }\end{array}$ & 2019 & $\begin{array}{c}\text { Estudo Transversal } \\
\text { Descritivo }\end{array}$ & $\begin{array}{l}\text { Apontar os benefícios da } \\
\text { fibrina rica em plaquetas. }\end{array}$ & $\begin{array}{l}\text { Constatou-se que PRF secreta maior } \\
\text { número de fatores de crescimento } \\
\text { quando comparados ao PRP, além de } \\
\text { poder ser utilizado em diversos } \\
\text { setores da cosmetologia. }\end{array}$ \\
\hline $\begin{array}{l}\text { Injectable platelet-rich fibrin } \\
\text { for facial rejuvenation: A } \\
\text { prospective, single-center study }\end{array}$ & 2020 & Estudo Qualitativo & $\begin{array}{l}\text { Estimar a eficácia de } \\
\text { fibrina rica em plaquetas } \\
\text { injetável (i-PRF) para } \\
\text { rejuvenescimento da pele } \\
\text { facial }\end{array}$ & $\begin{array}{l}\text { Os estudos mostraram que a injeção } \\
\text { intradérmica de fibrina rica em } \\
\text { plaquetas conseguiu melhorar } \\
\text { significativamente os sinais do } \\
\text { envelhecimento. Além disso, foi } \\
\text { observado uma melhora nas manchas } \\
\text { da pele e aparência dos poros. }\end{array}$ \\
\hline
\end{tabular}

Fonte: Autores (2021). 


\section{Discussão}

Segundo Sclafani e Saman (2012); Takamori et al. (2018) e Wang et al. (2019), a fibrina rica em plaquetas (PRF) é um biomaterial cuja sua principal propriedade é a quimiotaxia, sendo assim, é capaz de conduzir em sua superfície as migrações de células epiteliais e leucócitos, além de induzir condições adequadas para a microvascularização. Desta forma, a PRF é uma matriz de fibrina rica em plaquetas, citocinas, leucócitos, células estaminais e fatores de crescimento.

Em consonância ao exposto, Nacopolous et al. (2018), afirmam que essas propriedades da fibrina rica em plaquetas, possibilitam com que ela seja utilizada de forma tão profícua na proteção de feridas abertas, visto seu controle do processo inflamatório, corroborando como uma alternativa para acelerar o processo de cicatrização. Varela et al. (2018), relataram que esse concentrado plaquetário autólogo é utilizado quando se busca a cicatrização mais eficaz de tecidos duros e moles, devido a presença de fatores de crescimento e pela rápida angiogênese.

Inicialmente a utilização dos concentrados plaquetários nos procedimentos clínicos regenerativos surgiu pelo desejo dos cirurgiões em obter um biomaterial com melhores resultados no processo de cicatrização, sendo assim, os fatores de crescimento sanguíneos se destacaram nas pesquisas por induzir melhora das feridas cirúrgicas como apontam Takamori et al. (2018); Karimi e Rockwell (2019) e Hassan, Quinlan e Ghanem (2020). Deste modo, antes do desenvolvimento da PRF, o primeiro agregado plaquetário utilizado na tentativa de melhores resultados regenerativo foi o plasma rico em plaquetas (PRP) ou adesivos de fibrina (Miron et al., 2016).

Entretanto, Miron et al. (2016) advogam que o plasma rico em plaquetas deixou de ser utilizado visto que sua obtenção necessitava de aditivos como anticoagulante e agentes gelificantes, que acabavam induzindo efeitos colaterais indesejáveis como casos de hepatite. Surge então a fibrina rica em plaquetas, que consiste no sangue coletado do próprio paciente e centrifugado sem inclusão de aditivos. Seus primeiros registros foram registrados na França, no início dos anos 2000, por Joseph Choukroun que relatou a utilização deste biomaterial em várias aplicações intraorais e extraorais como relatam Sclafani e Azzi (2015).

Em concordância com estes estudos Sclafani et al. (2010); Takamori et al. (2018); Varela et al. (2018) e Karimi e Rockwell (2019), apontam inúmeras aplicações extraorais do PRF em procedimentos estéticos faciais, pois atua diretamente sobre o processo de cicatrização e evitando, em muitos casos, a formação de queloides para que então se obtenha um harmônico e satisfatório rejuvenescimento facial. Wang et al. (2019) destacam inclusive, que o PRF não apresenta toxicidade na pele, além de ser capaz por potencializar a migração de fibroblastos quando comparados ao plasma rico em plaquetas. Em um contexto clinico, isso significa que durante a regeneração local, as células ativadas são recrutadas para os tecidos defeituosos após a aplicação.

Ao avaliar a eficácia do PRF na correção de sucos nasolabiais profundos, Sclafani et al. (2010), relataram que dos 15 colaboradores adultos que participaram do estudo, onde foi coletado incialmente $9 \mathrm{ml}$ de sangue de cada paciente e transferidos em tubos para uma centrifuga de $1100 \mathrm{rpm}$, durante 6 minutos e então injetados após anestesia local. Todos os pacientes tiveram uma correção significativa nos sulcos nasolabiais profundos, nenhuma fibrose foi diagnosticada ou alguma irregularidade durante o tempo de tratamento. O que sugere a efetividade deste biomaterial, sem a necessidade de anticoagulantes aditivos, além de promover um aumento significativo na estimulação cutânea.

Sclafani e Saman (2012); Miron et al. (2016), apontam que dentre as vantagens de se usar a fibrina rica em plaquetas na face, é que este concentrado estimula a liberação de fatores de crescimento a longo prazo e auxilia no processo de reparo. Além disso, a matriz de PRF evita os efeitos indesejáveis dos leucócitos na pele. De forma categórica afirma ser um procedimento seguro, pouco invasivo, com a capacidade de estimular os vasos sanguíneos e melhorar a capacidade cicatricial do paciente. 
Em vista disso, Sclafani e Azzi (2015), avigoram através de um estudo de revisão de literatura, onde 61 trabalhos por diferentes autores, que abordavam quanto ao uso de agregados plaquetários na face, foram analisados por suas metodologias e triados a partir de estudos in vitro, estudos em animais e ensaios de casos clínicos. Concluíram que os agregados plaquetários PRF e PRP demonstraram resultados significativos. No que se refere a cicatrização no rosto o plasma rico em plaquetas demonstrou efeito mais rápido, enquanto que a fibrina rica plaquetas liberou fatores de crescimento mais lentamente a longo prazo. Entretanto, destacam que devido à ausência de aditivos exógenos em seu preparo, a PRF é o concentrado mais seguro e estável.

Takamori et al. (2018), após analisar o preparo, controle de qualidade e uso clinico da PRF nos atendimentos estéticos faciais, foi expressado que o uso de agregados plaquetários são eficazes para melhorar a cicatrização e promover a regeneração tecidual, salientaram também que este concentrado se constitui de uma matriz autóloga de fibrina, que libera citocinas a longo prazo, o que explica a otimização nos casos de cicatrização e estimula a migração de fibroblastos da pele, além de melhorar a síntese de colágeno. Evidenciado também por Wang et al. (2019), onde relataram que os pacientes apresentaram uma melhoria contínua, sem irregularidades no local que recebeu o tratamento.

No que se refere aos benefícios da fibrina rica em plaquetas na cosmética, Hassan, Quinlan e Ghanem (2020), descrevem com precisão as funções e as vantagens da PRF. Umas das experiencias relatadas foi a utilização injetável como preenchedor dérmico, que resultou na restauração do volume das cavidades lacrimais, atenuação das linhas finas e homogeneidade na irregularidade de pigmentação. Além disso, verificaram que durante o tratamento, à medida que o corpo metabolizava o material preenchedor, eram liberados fatores do crescimento responsáveis pelo depósito de colágeno.

Os autores Karimi e Rockwell (2019), também relatam os benefícios do PRF em procedimentos invasivos, como as cirurgias plásticas e garantem que este concentrado plaquetário, desempenha um papel significativo durante a cicatrização, pois promove excelentes respostas de coagulação. $\mathrm{O}$ estudo também aborda os benefícios da fibrina rica em plaquetas na queda de cabelo, em rinoplastias e também enxerto de gordura. Portanto, garantem que a utilização deste agregado plaquetário é eficaz na medicina cosmética, pois estimulam as células dérmicas, liberam fatores do crescimento e auxiliam na regeneração tecidual, entretanto estudos ainda são necessários para concretizar seus reais efeitos a longo prazo

Por fim, no que diz respeito a eficácia da fibrina rica em plaquetas na modalidade injetável (i-PRF), Nacopolous et al. (2018); Varela et al. (2018), afirmam que as aplicações intradérmicas deste concentrado foram utilizadas para o rejuvenescimento da pele, os resultados mostraram uma atenuação nas manchas da pele, além de ter melhorado a textura, rugas e linhas finas de expressão. Pacientes relataram satisfação com as bochechas, com a parte inferior da face e linha da mandíbula e satisfação com os lábios. Concluindo que após uma série de 3 injeções intradérmicas de PRF injetável, houve um resultado significativo da pele do rosto durante o período de 3 meses.

Desta forma, os trabalhos analisados revelaram que o emprego da fibrina rica em plaquetas de administração tópica ou injetáveis, tem efeitos significativos nos tratamentos estéticos da face e otimizam a cicatrização de feridas, não foi registrado nenhuma complicação biológica ou alteração sistêmica dos pacientes após a aplicação. Entretanto ao visualizar os trabalhos realizados nos últimos 10 anos, deve-se considerar a necessidade de conduzir trabalhos clínicos mais robustos e abrangentes com este biomaterial.

\section{Considerações Finais}

Em virtude dos resultados analisados, podemos concluir que as matrizes de fibrina rica em plaquetas, têm resultados significativos para a estética facial e tratamento dos sinais de envelhecimento, bem como apresenta efeito potencializador na cicatrização de feridas e regeneração da pele, sendo sobretudo um procedimento seguro, estável e de fácil preparo. Dado o 
exposto, o uso dessa técnica pode trazer benefícios profícuos para os pacientes, porém ainda deve haver maior divulgação e estudos científicos, objetivando o aprimoramento da técnica e a padronização dos protocolos.

\section{Referências}

Aires, C. C. G., Figueiredo, E. L., Pereira, V. B. S., Vasconcellos, R. J. H., Sabino, M. E. B. O., \& Medeiros, M. F. (2020). Regenerative therapies in implant dentistry: advances in application of platelet rich fibrin (PRF). Reas/Ejch. 1(39). 1-8.

Figueira, O., Casellas, J., Figueira, A., \& Perini, C. C. (2021). A luta contra o envelhecimento, uma análise na perspectiva bioética. Research, Society and Development. 10(1). e56210112254.

Gračanin, A., Krahmer, E., Balsters, M., Küster, D., \& Vingerhoets, A. (2017). Interactive effects of tears and muscular facial expressions. International Society for Research on Emotion Conference. 7(1). 26-29.

Hassan, H., \& Quinlan, D. J. (2020). Injectable platelet-rich fibrin for facial rejuvenation: A prospective, single-center study. J Cosmet Dermatol. 19(12), 3213-3221.

Henrique, A. S., \& Lopes, G. C. (2017). Biodiversidade e a indústria de cosméticos: o uso dos flavonoides contra o envelhecimento cutâneo. Revista Uningá Review. 29(2). 58-63.

Karimi, K., \& Rockwell, H. (2019). The Benefits of Platelet-Rich Fibrin. Facial Plast Surg Clin N Am. 27(1), 331-340.

Miron, R. J., Masako, F. K., Hernandez, M., Kandalam, U., Zhang, Y., Ghanaati, S. \& Choukroun, J. (2016). Injectable platelet rich fibrin (i-PRF): opportunities in regenerative dentistry? Clin Oral Investig. 21(8). 2619-2627.

Novais, M. J. A., \& Souza, E. P. (2020). Use of aesthetic treatments to delay cutaneous aging: integrative review. Open Journal Systems. 14(53). 950-961.

Nacopoulos, C., Gkouskou, K., Karypidis, D., Vlastos, I., Vesala, A. M., Choukroun, J., Miron, R. J., \& Prokopakis, E. (2018). Telomere length and genetic variations affecting telomere length as biomarkers for facial regeneration with platelet-rich fibrin based on the low-speed centrifugation concept. $J$ Cosmet Dermatol. 18(1), 408-413.

Oliveira, R. K. B., \& Sarmento, A. M. M. F. (2019). O uso dos óleos essenciais de gerânio e junípero no rejuvenescimento facial. 2 (1). 38-52.

Otárola, W. E., Núñez, G. C., Vaz, L. G., \& Kuga, M. C. (2016). Fibrina rica en plaquetas (FRP): Una alternativa terapéutica en odontologia. Rev Estomatol Herediana. 26(3), 173-178.

Pariol, C. L. L., Bovolini, T. T., Sardinha, L. S., \& Lemos, V. A. (2019). A influência da autoestima no processo do envelhecimento. Diálogos Interdisciplinares. 8(1). 45-52.

Pereira, A. S., Shitsuka, D. M., Parreira, F. J., \& Shitsuka, R. (2018). Metodologia da Pesquisa Científica. UFSM.

Sclafani, A. P. (2010). Platelet-rich fibrin matrix for improvement of deep nasolabial folds. Journal of Cosmetic Dermatology. 9(1). 66-71.

Sclafani, A. P., \& Azzi, J. (2015). Platelet Preparations for Use in Facial Rejuvenation and Wound Healing: A Critical Review of Current Literature. Aesth Plast Surg. 39(1), 495-505.

Sclafani, A. P., \& Saman, M. (2012). Platelet-Rich Fibrin Matrix for Facial Plastic Surgery. Facial Plast Surg Clin N Am. 20(1), $177-186$.

Silva, F. B., Dutra, K. M., Albuquerque, A. F. M., \& Filho, J. F. F. (2016). Evidências científicas do uso da fibrina rica em plaquetas em odontologia: uma revisão integrativa. Encontro de Extensão, Docência e Iniciação Científica. 12(1). 1-4.

Silva, M. R. \& Rodrigues, L. R. (2020). Conexões e interlocuções entre autoimagem, autoestima, sexualidade ativa e qualidade de vida no envelhecimento. Rev Bras Enferm. 73(3). e20190592.

Sinigaglia, G., Führ, T. (2019). Microagulhamento: uma alternativa no tratamento para o envelhecimento cutâneo. Revista Destaques Acadêmicos. 11(3), 1831 .

Souza, M. T., Silva, M. D., \& Carvalho, R. (2010). Revisão integrativa: o que é e como fazer. Rev Einstein, 8(1), $102-6$.

Takamori, E. R., Teixeira, M. V. T., Menezes, K., Carias, R. B. V., \& Borojevic, R. (2018). Fibrina rica em plaquetas: preparo, definição da qualidade, uso clínico. Vigil Sanit Debate. 6(1), 118-124.

Tchemra, F. G. C., Rezende, M., Morelli, F. M., Medeiros, S. T. C. B., \& Diniz, A. G. (2021). Platelet-Rich Fibrin (PRF) effectiveness in maxillary sinus lift: case report. Research, Society and Development. 10(1). e29210111492.

Varela, H. A., Souza, J. C. M., Nascimento, R. M., Junior, R. F. A., Vasconcelos, R. C., Cavalcante, R. S., Guedes, P. M., \& Araújo, A. A. (2018) Injectable platelet rich fibrin: cell content, morphological, and protein characterization. Clin Oral Invest. 23(3), 1309-1318.

Wang, X., Yang, Y., Zhang, Y., \& Miron, R. J. (2019). Fluid platelet-rich fibrin stimulates greater dermal skin fibroblast cell migration, proliferation, and collagen synthesis when compared to platelet-rich plasma. J Cosmet Dermatol. 18(3), 1-7. 